\title{
Distinct Features and Functions of Systemic and Mucosal Humoral Immunity Among SARS-CoV-2 Convalescent Individuals
}

\section{OPEN ACCESS}

Edited by:

Francesca Chiodi,

Karolinska Institutet (KI), Sweden

Reviewed by:

Marianne Jansson,

Lund University, Sweden

Lucia Lopalco,

San Raffaele Hospital (IRCCS), Italy

*Correspondence:

Peter F. Wright

Peter.F.Wright@hitchcock.org

Margaret E. Ackerman

margaret.e.ackerman@dartmouth.edu

${ }^{\dagger}$ These authors have contributed equally to this work

Specialty section:

This article was submitted to

Viral Immunology,

a section of the journal

Frontiers in Immunology

Received: 18 October 2020

Accepted: 21 December 2020

Published: 28 January 2021

Citation:

Butler SE, Crowley AR, Natarajan $H$,

Xu S, Weiner JA, Bobak CA,

Mattox DE, Lee J, Wieland-Alter W,

Connor Rl, Wright PF and

Ackerman ME (2021) Distinct Features and Functions of Systemic

and Mucosal Humoral

Immunity Among SARS-CoV-2

Convalescent Individuals.

Front. Immunol. 11:618685.

doi: 10.3389/fimmu.2020.618685
Savannah E. Butler ${ }^{1 \dagger}$, Andrew R. Crowley $^{1 \dagger}$, Harini Natarajan ${ }^{1 \dagger}$, Shiwei $X u^{2}$, Joshua A. Weiner ${ }^{3}$, Carly A. Bobak ${ }^{2}$, Daniel E. Mattox ${ }^{4}$, Jiwon Lee ${ }^{3}$, Wendy Wieland-Alter ${ }^{5}$, Ruth I. Connor ${ }^{5}$, Peter F. Wright ${ }^{5 *}$ and Margaret E. Ackerman ${ }^{1,2,3 *}$

1 Department of Microbiology and Immunology, Geisel School of Medicine at Dartmouth, Dartmouth College, Hanover, NH, United States, 2 Program in Quantitative and Biology Sciences, Dartmouth College, Hanover, NH, United States, ${ }^{3}$ Thayer School of Engineering, Dartmouth College, Hanover, NH, United States, ${ }^{4}$ Department of Computer Science, Dartmouth College, Hanover, NH, United States, ${ }^{5}$ Department of Pediatrics, Geisel School of Medicine at Dartmouth, DartmouthHitchcock Medical Center, Lebanon, NH, United States

Understanding humoral immune responses to SARS-CoV-2 infection will play a critical role in the development of vaccines and antibody-based interventions. We report systemic and mucosal antibody responses in convalescent individuals who experienced varying severity of disease. Whereas assessment of neutralization and antibody-mediated effector functions revealed polyfunctional antibody responses in serum, only robust neutralization and phagocytosis were apparent in nasal wash samples. Serum neutralization and effector functions correlated with systemic SARS-CoV-2-specific IgG response magnitude, while mucosal neutralization was associated with nasal SARS-CoV-2specific IgA. Antibody depletion experiments support the mechanistic relevance of these correlations. Associations between nasal IgA responses, virus neutralization at the mucosa, and less severe disease suggest the importance of assessing mucosal immunity in larger natural infection cohorts. Further characterization of antibody responses at the portal of entry may define their ability to contribute to protection from infection or reduced risk of hospitalization, informing public health assessment strategies and vaccine development efforts.

Keywords: antibody, mucosal immunity, IgA, IgG, neutralization, SARS-CoV-2, COVID-19, systems serology

\section{INTRODUCTION}

Since its emergence in late 2019 in China's Hubei province, SARS-CoV-2, the human coronavirus (CoV) causing COVID-19 disease, has spread rapidly. Formal designation as a pandemic followed in March of 2020, making understanding the health implications of infection and the development of effective interventions a global priority. To this end, studies of immune responses to endemic, other pathogenic $\mathrm{CoV}$ strains, and SARS-CoV-2 following infection will contribute to our 
understanding of how antibodies (Abs) might provide protection from infection or severe disease, or alternatively, contribute to disease pathology.

Due to the critical role of the $\mathrm{CoV}$ spike (S) protein in viral entry, Abs targeting $S$, particularly in the receptor binding domain (RBD), have demonstrated their ability to neutralize the infectivity of CoVs (1-5) including SARS-CoV-2 (6-8). Studies of monoclonal Abs isolated from SARS-CoV-2-infected individuals have shown potent anti-viral effects in vitro and protected against viral challenge in mouse, hamster, and nonhuman primate models (9-19), motivating monoclonal antibody-based therapies. Similarly, polyclonal $\mathrm{Ab}$ responses in convalescent and vaccinated hamsters and macaques have demonstrated protective efficacy in challenge experiments (2024). Collectively, these studies establish firm proof of principle for Ab-mediated protection and provide a rationale for the passive transfer of polyclonal serum Abs from recovered individuals as a clinical intervention (25-29).

While information on systemic immunity to SARS-CoV-2 continues to rapidly accrue (30-32), considerable uncertainty still surrounds the role of mucosal immunity to the virus within the respiratory tract, the primary site of SARS-CoV-2 infection and replication (33). Because immune responses can exhibit striking compartmentalization, mucosal immunity induced by natural infection and candidate vaccines administered parenterally may be quite divergent. Indeed, the lack of mucosally-targeted vaccines that have advanced to clinical trials is of some concern (34). While it appears that strong systemic IgG responses can protect against or reduce infection in the lower respiratory tract in animal models (21-24), it may be that Abs in the upper respiratory tract are needed to substantially limit virus replication at this site (34).

Indeed, early work to delineate $\mathrm{Ab}$ responses to human (35) and animal CoV (36-38) suggests that the induction of mucosal $\mathrm{Ab}$ is a key component in reducing viral shedding after infection and may mediate protective immunity following re-exposure. Studies of mucosally-targeted SARS-CoV-1 vaccines in animal models have identified that virus-specific mucosal IgA mediates protection against subsequent exposure to wild-type CoV (39, 40). These observations suggest that strategies to prevent SARS$\mathrm{CoV}-2$ infection will benefit from effective induction of not only robust systemic immunity, but also functional mucosal immunity to prevent or limit infection at the portal of entry (41). Thus, robust preexisting or induced mucosal immunity could reduce the risk of transmission within the community by decreasing the level or duration of viral shedding from infected individuals.

\section{METHODS}

\section{Human Subjects}

A total of 35 individuals were studied (Supplemental Table 1); 20 who had recovered from COVID-19 (age range: 18-77, mean: 53 years) and 15 naïve control subjects (age range: 22-66, mean: 40 years). Infection with SARS-CoV-2 was confirmed by PCR of nasopharyngeal swab for all COVID-19 patients. Study subjects included both males (17) and females (18). Disease severity among COVID-19 subjects ranged from mild (4) to moderate (12) and severe (4). Classification of mild and moderate disease was based individuals self-reporting whether or not their symptoms influenced activities of daily life, while a designation of severe disease was made on the basis of hospitalization for COVID-19. Serum, nasal wash, and stool samples were collected from each donor approximately 1 month after symptom onset (range: 19-67 days, mean: 38 days).

Primary neutrophils used in functional assays were purified from deidentified blood samples from healthy male and female donors over the age of 18 years. All research involving human subjects was approved by the Dartmouth College and Dartmouth-Hitchcock Medical Center Committee for the Protection of Human Subjects (Institutional Review Board) and written informed consent was obtained from all participants.

\section{Antigen and Fc Receptor Expression and Purification}

Prefusion-stabilized, trimer-forming spike protomers (S-2P) of SARS-CoV-2, closely related and/or epidemic strains (SARSCoV-1, WIV1, and MERS), and endemic coronaviruses (229E, OC43, NL63, and HKU1), and the receptor-binding domain of SARS-CoV-2 fused to a monomeric form of the human IgG4 Fc region were transiently expressed in either Expi 293 or Freestyle 293-F cells, and purified via affinity chromatography according to the manufacturers' protocols (Supplemental Tables 2 and 3). Human FcgR were expressed and purified as described previously (42).

\section{Fc Array Assay}

$\mathrm{CoV}$ and control antigens, including $\mathrm{S}$ trimers, $\mathrm{S}$ subdomains (i.e., S1 and S2), and other viral proteins from SARS-CoV-2 as well as $\mathrm{S}$ and S subdomains from SARS CoV-1, MERS, HKU1, OC43, NL63, 229E, and WIV1 (Supplemental Table 2) and influenza HA and herpes simplex virus (HSV) gE proteins were covalently coupled to Luminex MagPlex magnetic microspheres using a two-step carbodiimide chemistry as previously described (43). Biotinylated SARS-CoV-2 fusion peptide was captured on neutravidin-coupled microspheres. Pooled polyclonal serum IgG (IVIG), CR3022, a SARS CoV-1-specific monoclonal Ab that cross-reacts with SARS-CoV-2 S (11), and VRC01, an HIVspecific monoclonal $\mathrm{Ab}$, were used as controls to define the antigenicity profiles. The optimal dilution of serum was determined in pilot experiments in which a subset of samples was titrated. Test concentrations for serum ranged from 1:250 to 1:5000 and varied per detection reagent. Nasal wash and stool samples were assayed at a 1:10 dilution. Isotypes and subclasses of antigen-specific Abs were detected using R-phycoerythrin (PE) conjugated secondary Abs and by FcRs tetramers (Supplemental Table 4) as previously described $(44,45)$. A FlexMap 3D array reader detected the beads and measured PE fluorescence used to calculate the Median Fluorescence Intensity (MFI). 


\section{Neutralization Assay}

Samples of serum and nasal wash from SARS-CoV-2 convalescent and naïve donors were tested in microneutralization assays using a VSV-SARS-CoV pseudovirus system (46). In brief, samples were serially diluted 2-fold (1:50-1:3200 for serum; 1:4-1:256 for nasal wash) and incubated with a standardized concentration of SARS-CoV-2 pseudovirus for $1 \mathrm{~h}$ at $37^{\circ} \mathrm{C}$ followed by addition to duplicate wells of 293T-ACE2-expressing target cells (Integral Molecular, Philadelphia PA) in a final volume of $100 \mu \mathrm{l}$ per well. Plates were incubated at $37^{\circ} \mathrm{C}$ for $18-24 \mathrm{~h}$, after which luciferase activity was measured using the Bright-Glo system (Promega, Madison WI) in a Bio-Tek II plate reader. Results were quantified relative to controls and data expressed as $60 \%$ neutralization titers.

\section{Phagocytosis Assays}

Assays of Ab-dependent phagocytosis by monocytes (ADCP) and neutrophils (ADNP) were performed essentially as described (4749). Briefly, $1 \mu \mathrm{m}$ yellow-green fluorescent microspheres (Thermo, F8813) were covalently conjugated with recombinant RBD and incubated for $3 \mathrm{~h}$ with dilute serum or nasal wash specimens and either the human monocytic THP-1 cell line (ATCC, TIB-202), or with freshly-isolated primary neutrophils. After pelleting, washing, and fixing, phagocytic scores were quantified as the product of the percentage of cells that phagocytosed one or more fluorescent beads and the median fluorescent intensity of this population as measured by flow cytometry with a MACSQuant Analyzer (Miltenyi Biotec). ADCP assays were performed in duplicate with high correspondence between results presented here and the replicate run. ADNP assays were performed in biological replicate using neutrophils purified from two different healthy donors for which results were averaged. A subset of neutrophils was stained with CD66b-APC (BioLegend G10F5) and PI (Biotium 41007) to determine the purity and viability of the isolated cellular fraction. CR3022 and VRC01 were used as positive and negative controls, respectively. Wells containing no Ab were used to define the level of Ab-independent phagocytosis.

\section{CD16 Reporter Assay}

The ADCC potential of the specimens was measured using a Jurkat Lucia NFAT cell line (Invivogen, jktl-nfat-cd16), cultured according to the manufacturer's recommendations, in which engagement of FcyR3a (CD16) on the cell surface leads to the secretion of luciferase. One day prior to running the assay, a high binding 96 well plate was coated with $1 \mu \mathrm{g} / \mathrm{ml}$ SARS-CoV-2 RBD at $4^{\circ} \mathrm{C}$ overnight. Plates were then washed with $\mathrm{PBS}+0.1 \%$ Tween 20 and blocked at room temperature for $1 \mathrm{~h}$ with PBS + $2.5 \%$ BSA. After washing, dilute serum or nasal wash sample and 100,000 cells/well in growth medium lacking antibiotics were cultured at $37^{\circ} \mathrm{C}$ for $24 \mathrm{~h}$ in a $200 \mu \mathrm{l}$ volume. The following day, $25 \mu$ of supernatant was drawn from each well and transferred to an opaque, white 96 well plate, to which $75 \mu$ l of QuantiLuc substrate was added and luminescence immediately read on a SpectraMax Paradigm plate reader (Molecular Devices) using $1 \mathrm{~s}$ of integration time. The reported values are the mean of three kinetic reads taken at $0,2.5$, and $5 \mathrm{~min}$. Negative control wells substituted assay medium for sample while $1 \mathrm{x}$ cell stimulation cocktail (Thermo, 00-4970-93) plus an additional $2 \mu \mathrm{g} / \mathrm{ml}$ ionomycin were used to induce expression of the transgene as a positive control.

\section{Complement Deposition Assay}

Antibody-dependent complement deposition (ADCD) was quantified essentially as previously described (50). In brief, serum and nasal samples were heat-inactivated at $56^{\circ} \mathrm{C}$ for 30 min prior to a $2 \mathrm{~h}$ incubation at a dilution of 1:20 at RT with multiplex assay microspheres. After washing, each sample was incubated with human complement serum (Sigma, S1764) at a concentration of 1:50 at RT with shaking for $1 \mathrm{~h}$. Samples were washed, sonicated, and incubated with murine anti-C3b (Cedarlane \#CL7636AP) at RT for $1 \mathrm{~h}$ followed by anti-mouse IgG1-PE secondary Ab (Southern Biotech \#1070-09) at RT for 30 min. After a final wash and sonication, samples were resuspended in Luminex sheath fluid and complement deposition was determined on a MAGPIX (Luminex Corp) instrument to define the MFI. Assays performed without $\mathrm{Ab}$ and with heat-inactivated human complement serum were used as negative controls.

\section{Immunoglobulin Depletion}

The antibody isotypes present in nasal wash samples were selectively depleted using resins targeting IgG (CaptureSelect IgG CH1 affinity matrix, Thermo, 194320005), IgA (CaptureSelect IgA affinity matrix, Thermo, 194288005), or IgM (POROS CaptureSelect IgM affinity matrix, Thermo, 195289005). Microcentrifuge spin columns (Thermo, 69705) were loaded with $50 \mu \mathrm{l}$ of suspended resin, followed by equilibration of the resin by passing PBS through the column. Nasal wash samples were diluted 1:10 in PBS and $150 \mu \mathrm{l}$ were added to the column and incubated with end-over-end mixing for $5 \mathrm{~min}$ at room temperature. The remaining volume of the diluted sample was saved for use as the mock-depleted control. The isotype-depleted flow through was collected in a clean microcentrifuge tube and the columns were regenerated with $100 \mathrm{mM}$ glycine $(\mathrm{pH} 3.0)$ and equilibrated before reuse. The extent of on- and off-target depletion of $\operatorname{IgG}, \operatorname{IgA}$, and $\operatorname{IgM}$ was measured using the Fc array assay described previously. The depleted samples were then evaluated in neutralization and phagocytosis assays as described above.

\section{Data Analysis and Visualization}

Basic analysis and visualization were performed using GraphPad Prism. Heatmaps, correlation plots, and boxplots were made in $\mathrm{R}$ (version 3.6.1 (51), supported by R packages pheatmap (52), corrplot (53), and ggplot2 (54)). Hierarchical clustering was used to cluster and visualize data using Manhattan or Euclidean distance. Fc Array features were filtered by elimination of measurements for which $>25 \%$ of the samples exhibited signal within 10 standard deviations (SD) of the technical blank. Fc array features were log transformed, then scaled and centered by their standard deviation from the mean (z-score). Based on data distributions and the limited number of individuals who 
experienced severe disease, a student's two-tailed t-test with Welch's correction with a cutoff of $\mathrm{p}=0.05$ was used to define features different between groups and with the exception of depletion studies, Pearson correlation coefficients were calculated to define relationships between features. Nonparametric tests yielded qualitatively similar results; parametric test results are presented due to their interpretability and power advantage. All comparison results should be considered in the context of limitations of small cohort size. For depletion studies, Spearman correlation coefficients and two-tailed $p$ values were determined for the relationship between extent of depletion and extent of decrease in neutralization and phagocytosis, according to data distributions and the lack of an expectation of a monotonic linear relationship. Increases were considered to be within assay noise and set to zero. Cohort characteristic, Fc Array, and functional assay data is available at https://github. com/AckermanLab/Butler_et_al_COVID_2020.

\section{RESULTS}

\section{Systemic and Mucosal SARS CoV-2 Specific Ab Response Features}

To characterize and compare the systemic and mucosal humoral immune responses to SARS-CoV-2 and better understand the relationships between antibody features and functions within serum, nasal wash, and stool samples, we turned to systems serology (55). This technique utilizes high-throughput, multidimensional biophysical profiling of antibody response features, cell-based assays of $\mathrm{Ab}$ neutralization and effector functions, and machine learning as a means to discover mechanistically meaningful signatures of Ab-mediated protection and activity (56).

Serum, nasal wash, and stool samples were collected approximately 1 month after initial clinical presentation from 20 subjects who tested positive for SARS CoV-2 by qPCR, and from 15 SARS-CoV-2 naïve subjects (Supplemental Table 1). Recruitment of a larger cohort of convalescent subjects was limited by the low case burden in the area where these samples were obtained. Antibody responses to SARS-CoV-2 were evaluated using an Fc array $(44,45)$ to characterize isotypes, subclasses, and $\mathrm{Fc}$ receptor $(\mathrm{FcR})$ binding across $\mathrm{Abs}$ specific to a panel of SARS-CoV-2 antigens. This panel included stabilized trimeric spike protein (S-2P), subunits (i.e. S1, S2), and receptor binding domain (RBD) forms, nucleocapsid (N) protein, and the fusion peptide. $\mathrm{S}$ proteins from four other endemic $\mathrm{CoV}$ strains (OC43, HKU1, 229E, and NL63) and two non-CoV control antigens (influenza HA and herpes simplex virus $\mathrm{gE}$ ), were also evaluated.

SARS-CoV-2-specific Ab responses were observed in COVID-19-convalescent, but not naïve, donor sera, nasal wash, and stool (Figure 1A). Ab responses in serum and nasal wash samples were examined by measuring levels of $\mathrm{Ab}$ isotypes and subclasses, and by defining binding to diverse FcRs (Figure 1B, Supplemental Figures 1-6). SARS CoV-2specific IgG1, IgG2, IgG3, IgA, IgM, and immunoglobulin (Ig) able to ligate FcRs (Fc $\alpha \mathrm{R}, \mathrm{Fc} \gamma \mathrm{R}$ ) were observed among samples from convalescent donors but not naïve subjects. In contrast to the robust responses apparent in serum and nasal samples, limited SARS CoV-2 specific Ig was detected in stool samples (Figure 1A, Supplemental Figure 7). Robust responses to stabilized spike (S-2P) and $\mathrm{N}$ were observed, as were responses to functionally relevant $\mathrm{RBD}$ and fusion peptide domains.

Systematic analysis of the magnitude and statistical confidence of differences in $\mathrm{Ab}$ present in samples from convalescent versus naïve donors indicated elevated IgG, IgA, and IgM responses across diverse SARS CoV-2 antigens as well as a number of antigens from endemic and related beta-CoV (Figure 4A, Supplemental Figure 8). Among these, elevated levels of OC43 (29.7\% S amino acid identity) S-specific IgG and IgA in serum were particularly notable (unpaired two-tailed ttest with Welch's correction; $\mathrm{p}<0.0001$ and $\mathrm{p}=0.011$ respectively). This apparent boosting of responses to endemic $\mathrm{CoV}$ occurred more widely among IgG1 and IgG3 subclasses (Supplemental Figure 1) and was also apparent in nasal and stool samples (Supplemental Figures 4, 7).

\section{Neutralization Activity of Systemic and Mucosal Ab}

Given evidence of robust humoral responses in systemic and mucosal samples, we next sought to determine the neutralization potency of serum and nasal wash samples using a luciferasebased SARS-CoV-2 pseudovirus assay (46). Consistent with other studies (57), elevated serum neutralization activity was observed for hospitalized subjects who experienced severe, as compared to non-severe (i.e. mild and moderate cases), disease (unpaired two-tailed t-test with Welch's correction, $\mathrm{p}=0.034$ ) (Figure 2A). In contrast to observations made in serum, nasal samples from subjects with severe disease showed little to no viral neutralization, whereas subjects with elevated mucosal neutralization activity tended to report mild symptoms that did not influence activities in their daily lives or moderate symptoms that did influence activities but did not require hospitalization (Figure 2B). Interestingly, robust nasal and serum neutralization activities were not co-induced (Figure 2C).

\section{Effector Functions of Systemic and Mucosal Ab}

Beyond neutralization, little is known about the antiviral functions of systemic and mucosal Abs in COVID-19 convalescent donors. We characterized the antiviral effector functions of Abs in serum and nasal samples by evaluating Abmediated phagocytosis, NK cell receptor ligation and complement activation induced by RBD-specific antibodies. Serum from most convalescent subjects readily promoted phagocytosis mediated by monocyte (ADCP) and neutrophil (ADNP) effector cells (Figure 2A). While nasal wash samples were far less capable of driving functional activity, several subjects exhibited nasal $\mathrm{Ab}$ responses able to elicit phagocytosis in monocytes (Figure 2B). Serum from these subjects also tended to generate a strong phagocytic response 
A
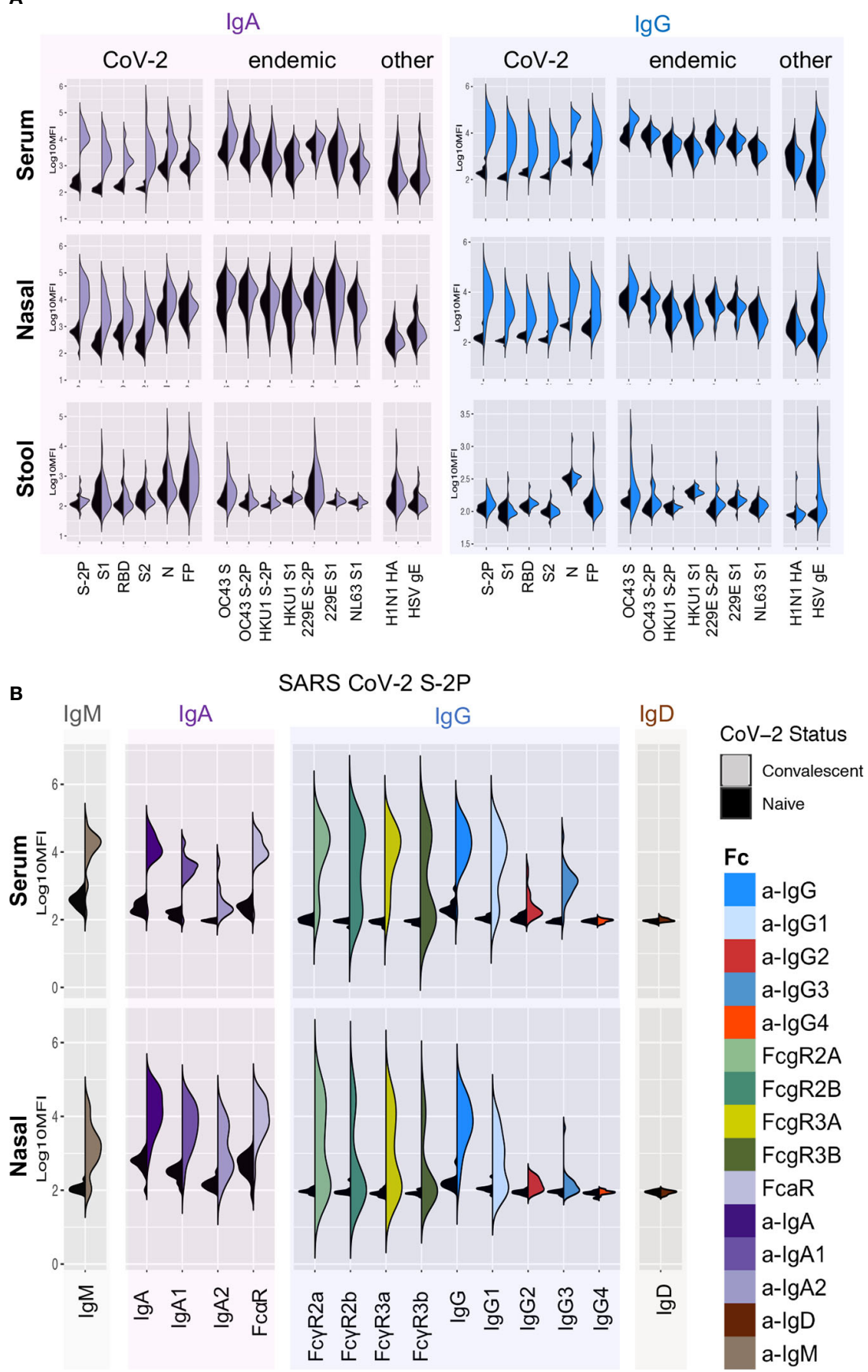

FIGURE 1 | Systemic and mucosal Ab responses. (A) FC array characterization of IgA (left) and lgG (right) responses against a panel of SARS-CoV-2, other CoV, and control antigens in serum (top), nasal wash (middle), and stool (bottom) from convalescent (colored) and naïve (black) donors. (B) Isotypes, subclasses, and FcR binding of Abs to stabilized SARS CoV-2 S (S-2P) in serum (top) and nasal wash (bottom).

(Figure 2C). Across phagocytosis, NK cell Fc $\gamma \mathrm{R} 3 \mathrm{a}$ receptor ligation (ADCC), and deposition of complement cascade protein $\mathrm{C} 3 \mathrm{~b}$ (ADCD), a pattern of elevated $\mathrm{Ab}$ effector function emerged among subjects who experienced moderate or severe disease; those who experienced mild disease generated little activity. In contrast to serum, but consistent with the lower relative levels of IgG detected, nasal wash initiated only limited ADNP, ADCC, and ADCD, whereas monocyte phagocytosis was apparent (Figure 2B), and directly correlated with ADCP activity in serum (Figure 2C). 

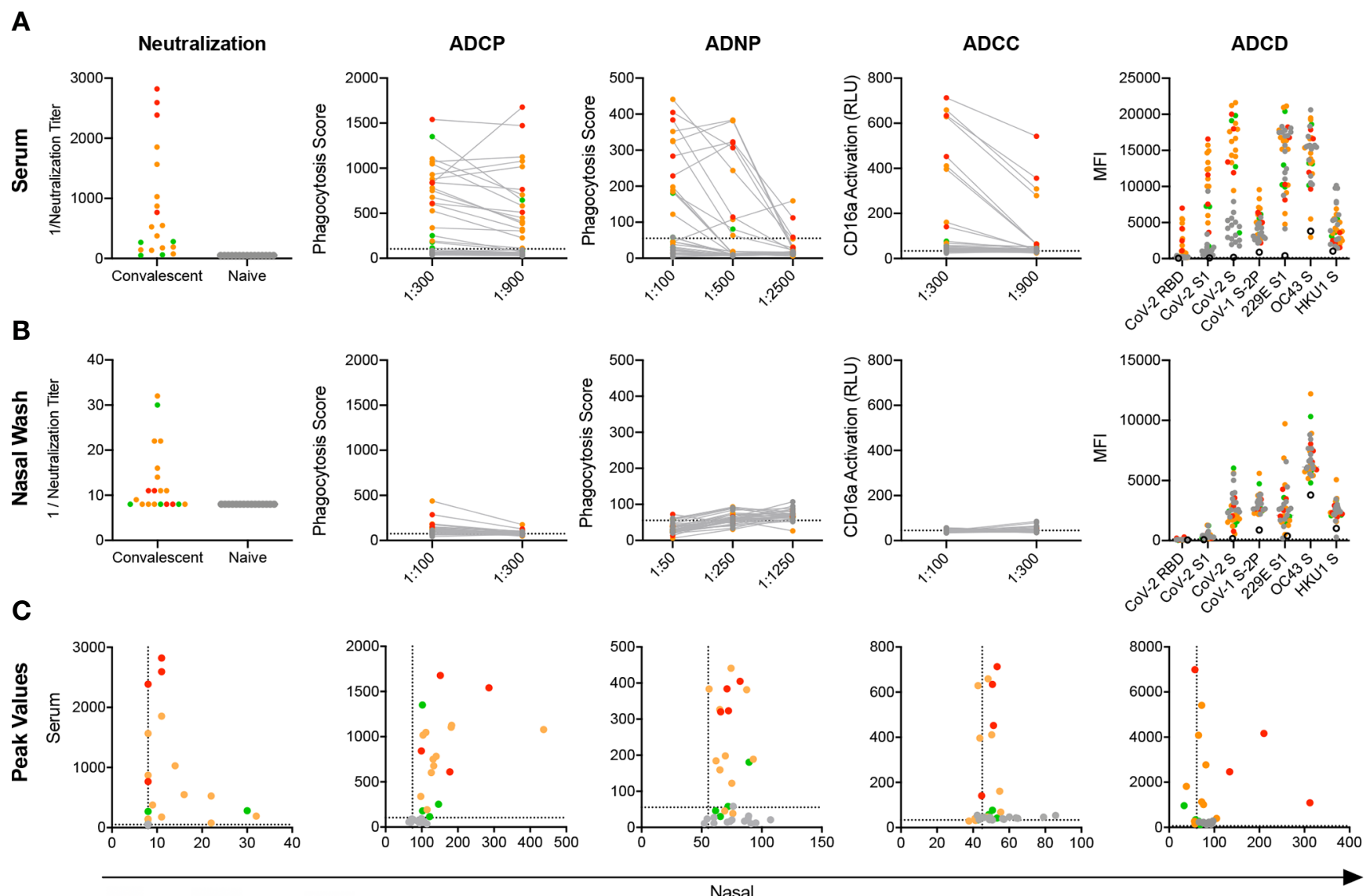

- Naive Mild Moderate Severe

Nasal

FIGURE 2 | Mucosal and systemic Ab functions. (A, B) Functional activity of serum (A, B) nasal wash subject samples in a panel of neutralization and effector function assays including antibody-dependent phagocytosis by monocytes (ADCP) and neutrophils (ADNP), action of FcyRIIIA (ADCC), and complement cascade C3b deposition (ADCD). (C) Scatterplots of serum versus nasal wash sample activities observed for each subject for viral neutralization and RBD-specific Ab effector functions. Titer is plotted for neutralization data and peak activity is plotted for effector functions. Infection status and disease severity is indicated in color. Limit of detection (neutralization) or values observed for no Ab controls (ADCP, ADNP, ADCC) are indicated with dotted lines. No Ab controls for ADCD are indicated with the hollow black circle.

\section{Functional Correlates in Serum and Mucosal Abs}

Next, we explored the characteristics of the Abs mediating each effector function by measuring correlations between RBDspecific $\mathrm{Ab}$ biophysical features and $\mathrm{Ab}$ functions in serum (Figure 3A). ADCP, ADNP, and ADCC activities were most strongly correlated with $\mathrm{Fc} \gamma \mathrm{R}$ binding, consistent with their reliance on this class of receptor, but also with levels of IgG1 and IgG3, which ligate Fc $\gamma$ R best among human IgG subclasses. Interestingly, IgM positively correlated with both ADNP and neutralization activity. While IgA responses were robustly induced in serum, this isotype was generally more weakly associated with neutralization and effector activities than IgG.

In nasal samples, however, neutralization activity positively correlated with the IgA response (Figures 3A, C; $\mathrm{R}_{\mathrm{P}}=0.67, \mathrm{p}=$ 0.0016). In comparison, and as in serum, ADCP showed significant correlation with total RBD-specific IgG and Fc $\gamma$ R- binding RBD-specific Abs $\left(\mathrm{R}_{\mathrm{P}}=0.86, \mathrm{p}<0.0001\right)$. Strong relationships with the other effector functions, which largely showed low or negligible levels of activity, were generally not observed. While serum Ab functions were significantly correlated with one another, this relationship was not seen in nasal wash samples (Figure 3B), attributable to the low activity observed for many functions. Representative scatterplots between individual features and functions show how these activities and characteristics varied by subject according to disease severity (Figure 3C).

\section{Relationships Between Systemic and Mucosal Ab Features}

Because mucosal and systemic responses can exhibit remarkable divergence (58), we next explored relationships among features of the humoral immune response between these two compartments. Following centering and scaling, hierarchical 
A
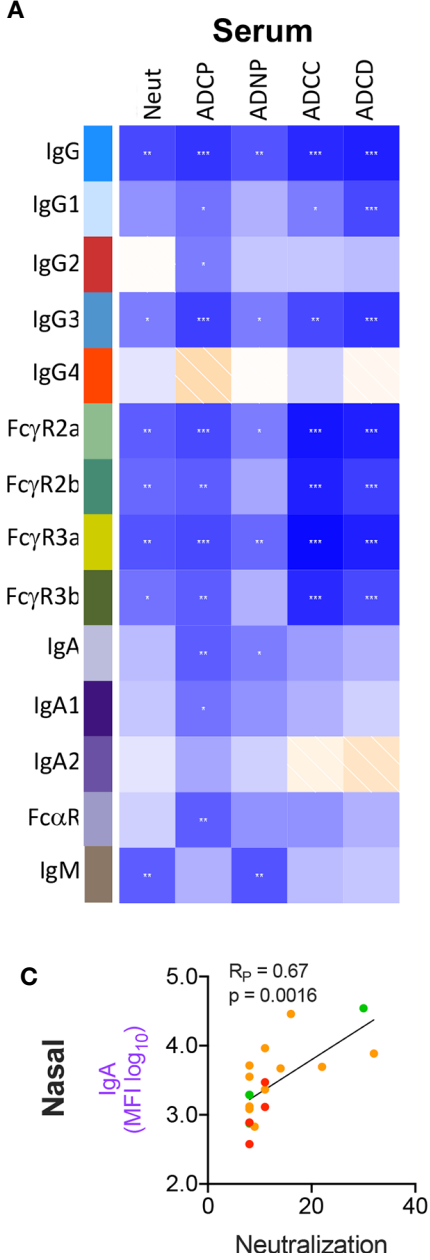
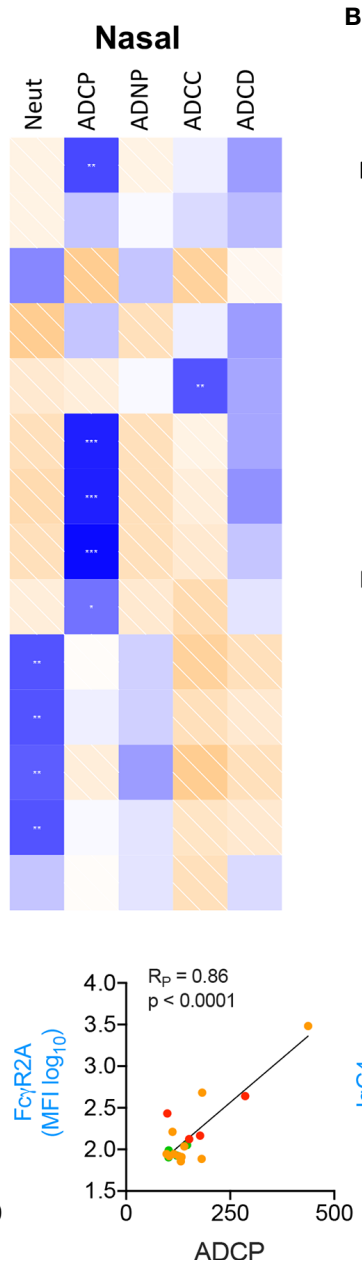
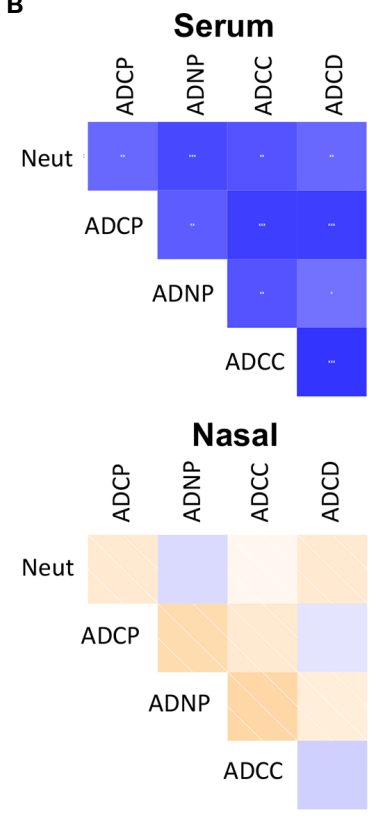

correlation coefficient $\left(R_{P}\right)$
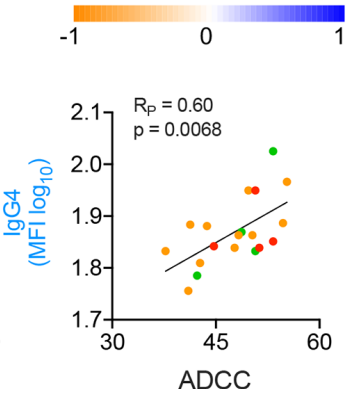

FIGURE 3 | Correlative relationships between RBD-specific Ab features and functions. (A) Correlations observed between RBD-specific Ab features and functions in serum (left) and nasal wash (right) samples. (B) Correlations observed between Ab functions observed in serum (top) and nasal wash (bottom). (C) Representative scatterplots between highly correlated Ab features and functions in nasal wash samples. p values from unpaired two tailed t-tests with Welch's correction. Pearson correlation coefficients $\left(R_{P}\right)$ are shown.

clustering of $\mathrm{Ab}$ features that were significantly increased among convalescent donors (unpaired two-tailed t-test with Welch's correction, $\mathrm{p}<0.05$, Supplemental Figure 8) was performed to define similarities between subjects and features (Figure 4A). Elevated IgG responses were apparent in both serum and nasal samples in convalescent donors who experienced severe disease. In contrast, donors with non-severe disease (mild or moderate) appeared to present elevated nasal IgA responses (Figure 4A, upper right).

Given this apparent dichotomy between isotypes, correlations between IgG and IgA within and between serum and nasal samples of convalescent donors were defined for a representative $S$ antigen (Figure $4 \mathbf{B}$ ). Serum and nasal $\mathrm{IgG}$ were directly correlated, as were serum and nasal IgA. However, no or inverse relationships were observed between IgG and IgA both within and between sample types. When expanding this analysis to all $\mathrm{Ab}$ types and specificities elicited among convalescent donors, clear patterns emerged suggesting global biases between IgA and IgG responses (Supplemental Figure 9A). For example, in serum, IgG1, IgG3, and Fc $\gamma$ Rbinding $\mathrm{Ab}$ responses correlated well with one another across diverse specificities; IgA, IgA1, IgA2, and FcoR-binding Abs did so too. Overall, correlations between IgG and IgA in serum were more modest, though many specific response features were positively correlated with each other. In contrast, nasal responses showed evidence of a dichotomy between isotypes with a tendency to favor either IgG or IgA across diverse antigen specificities (Figure 4B, Supplemental Figure 9B).

\section{Relationships Between Clinical Characteristics and Ab Responses}

Though power is limited by the small cohort, we explored how immune responses related to subject characteristics by defining the magnitude and statistical confidence of differences between subjects by age, sex, and disease severity (Supplemental Figure 10). Relatively few aspects of the antibody response differed 
A

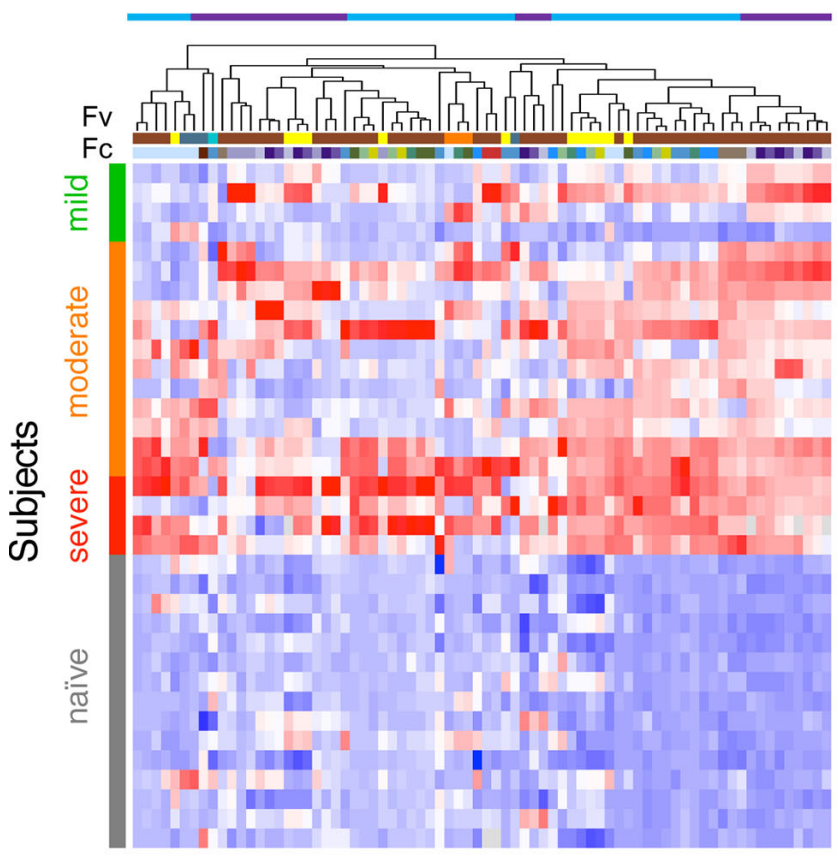

Serum Ab features

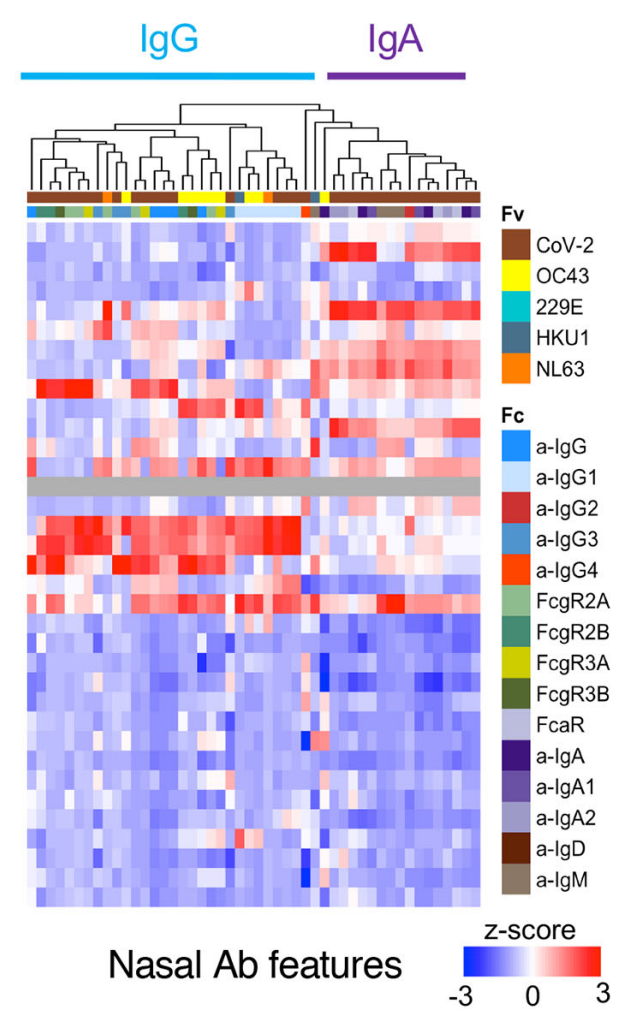

B

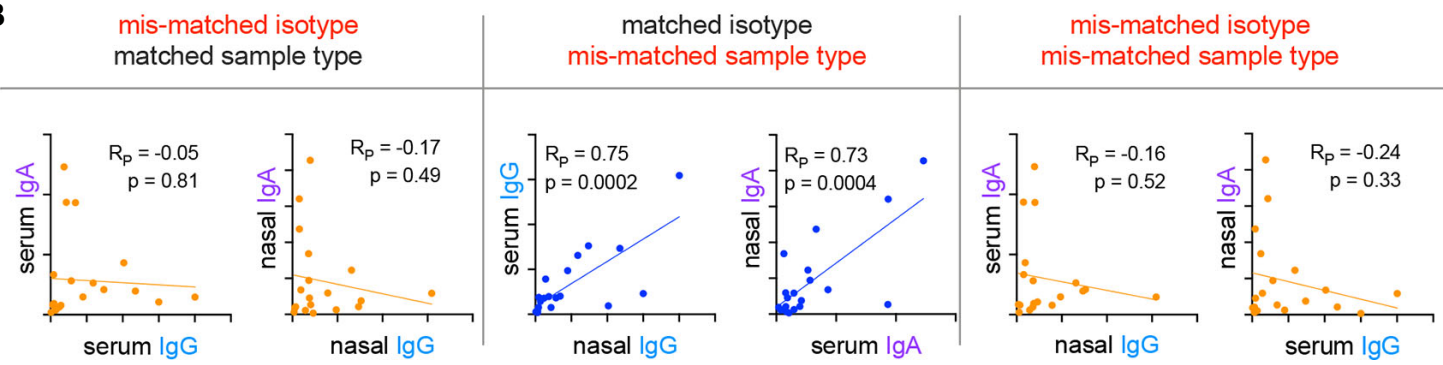

FIGURE 4 | Relationships among subjects and Ab features in serum and nasal wash. (A) Heatmap of filtered and hierarchically-clustered Fc array features in serum (left) and nasal wash (right) across subjects with varying infection or disease status. Each row represents an individual donor. Disease severity is shown on the left annotation bar. Each column represents an Fc Array measurement, with antigen specificity (Fv) and Fc characteristics (Fc) are indicated in top color bars. Responses are centered and scaled per feature and the scale range truncated at +/-3 SD. Relatively high responses are indicated in red, and low responses in blue. Color bars at bottom indicate the divergent clusters of lgG-related (blue) and lgA-related (purple) responses observed in nasal wash samples. (B) Representative scatter plots of the correlative relationships between IgA and lgG anti-S1 responses in nasal and serum samples. Pearson correlation coefficients $\left(R_{P}\right)$ and $p$ values of unpaired twotailed t-tests with Welch's correction are reported.

according to sex and age. These differences were considerably less pronounced than those observed to vary according to disease severity, though some exceeded a nominal significance threshold of $\mathrm{p}=0.05$, and thus may merit follow up in other cohorts.

In contrast, a greater number of features were more robustly and confidently distinct among individuals according to disease severity, though confidence is limited by the small number of subjects in the cohort who experienced severe disease. In exploratory analyses of serum and nasal wash samples, comparisons were performed to determine which $\mathrm{CoV}-2$ specific $\mathrm{Ab}$ features showed differences between individuals experiencing severe versus non-severe (mild or moderate) disease (unpaired two-sided test with Welch's correction, $\mathrm{p}<$ 0.05). As reported in other cohorts (57), a number of IgG-related responses were elevated in serum among individuals who had experienced severe disease (Supplemental Figure 11). One feature elevated in those with severe disease, CoV-2-specific antibodies interacting with $\mathrm{Fc} \gamma \mathrm{R} 3 \mathrm{a}$, was recently reported to also be associated with fatal disease (31). This heightened IgG response among hospitalized donors was also evident in nasal wash samples, whereas RBD-specific antibodies that bound Fc $\alpha$ R were significantly elevated in the nasal wash samples of subjects who had experienced mild or moderate disease (unpaired twosided test with Welch's correction, $\mathrm{p}=0.025$ ) (Figure 5A), 
A

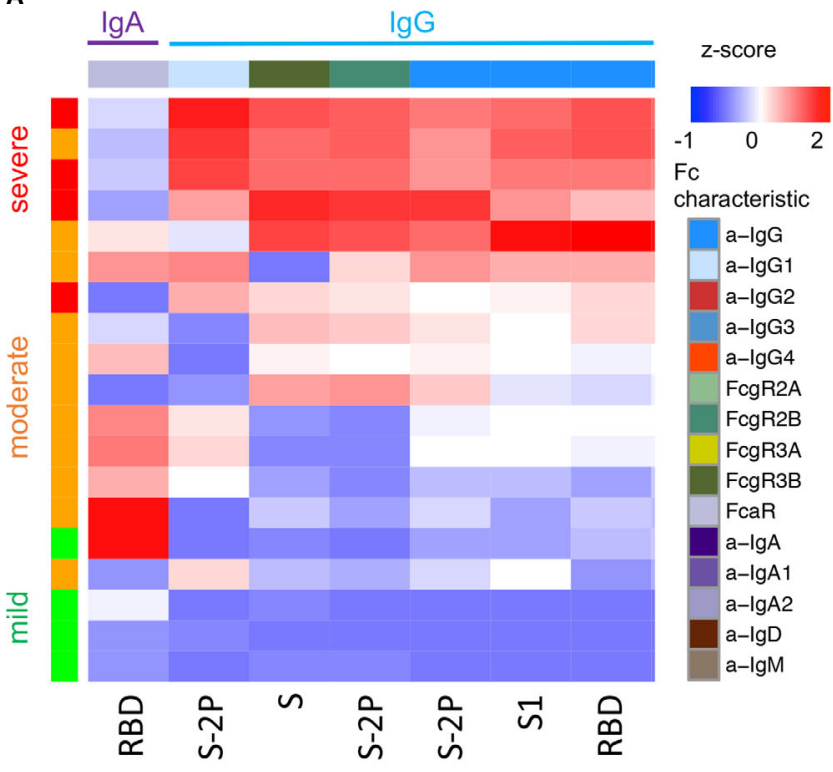

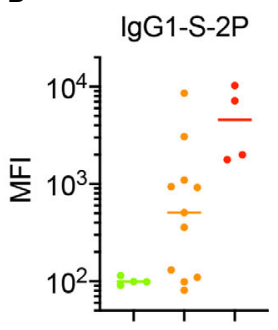

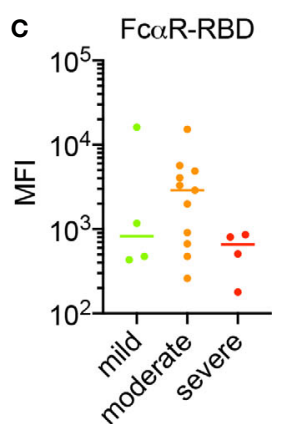

FIGURE 5 | Nasal Ab features associated with disease severity. (A) Heatmap of nasal CoV-2-specific Ab features that exhibited statistically significant differences in responses between subjects with severe and non-severe (mild or moderate) disease (unpaired two-sided t-test with Welch's correction, $\mathrm{p}<0.05)$. (B, C) Representative boxplots of nasal features by disease severity across donors who experienced mild, moderate, and severe disease. (B) IgG1 specific to S-2P as a representative Ab feature elevated among subjects with severe disease. (C) Fc $\alpha$ R binding Abs specific to RBD are highest among individuals who recovered from moderate disease as opposed to either mild or severe disease.

though this difference was not significant following Bonferroni correction. A number of other IgA-related responses exhibited differences near the nominal, unadjusted significance threshold (Supplemental Figure 10). When examining the relationships between these features among donors who recovered from mild, moderate, or severe disease, IgG-related features typically increased in magnitude uniformly alongside disease severity (Figure 5B). In contrast, the IgA-associated feature defined by nasal RBD-specific Abs binding to FcoR (Figure 5C) was lowest in subjects with either mild or severe disease, and elevated among a subset of those who recovered from moderate illness. Though differences between subjects experiencing moderate and mild disease or between those experiencing moderate and severe disease were not statistically significant (unpaired two-sided ttest with Welch's correction), this apparent "goldilocks" profile raises the hypothesis that IgA responses may contribute to protection from less severe disease, but, like IgG responses, may not always be elicited either systemically or mucosally by mild disease.

\section{Functional Impact of Ab Isotype Depletion}

Given the correlations between $\mathrm{Ab}$ isotypes and neutralization and other Ab-mediated effector functions, we sought to evaluate a mechanistic link by selective depletion of individual $\mathrm{Ab}$ isotypes from nasal wash samples. Samples from four subjects who had high neutralizing titers in both nasal wash and serum were selected for evaluation. Individual isotypes (IgG, IgA, IgM) were depleted via anti-isotype affinity resin and neutralization and phagocytic activity defined for mock treated and depleted samples (Supplemental Figure 12). The level of residual antibody in the depleted fractions was also quantified by multiplex assay. Because the extent of depletion of the intended isotype was variable and concomitant changes in other isotypes were observed, each depleted fraction was evaluated in comparison to a mock-depleted control to define the relationship between reduction of a given isotype and any subsequent decrease in neutralization or ADCP activity (Figure 6). Data points from each depletion were analyzed as though independent. Whereas depletion of IgG had no apparent impact on the neutralization potency of nasal wash samples, it directly correlated to decreases in phagocytosis $(p=0.0029)$. In contrast, depletion of IgA or IgM did not relate to changes in phagocytic activity, but was associated with reduced neutralization potency ( $p=0.051$ and $p=0.033$, respectively). While these observations result from a limited number of individuals, they raise the possibility that mucosal IgA is a functional component of neutralization of SARS-CoV-2 in the upper respiratory tract, which is consistent with a wealth of prior data on $\mathrm{CoV}$ in human and animal studies (35-40).

\section{DISCUSSION}

A paradox emerging from studies of SARS-CoV-2 in naturally infected cohorts is that the highest $\mathrm{Ab}$ titers and most potent neutralizing $\mathrm{Ab}$ responses, known to associate with protection in 
A
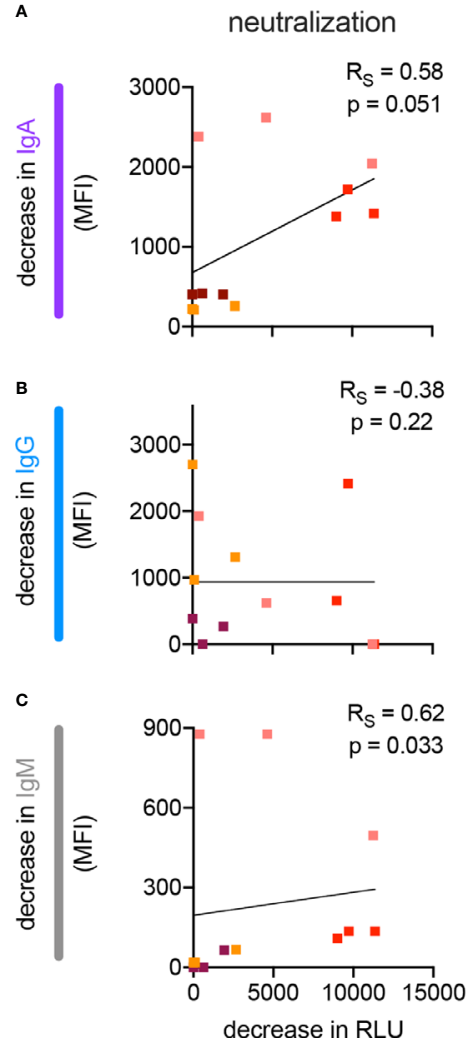
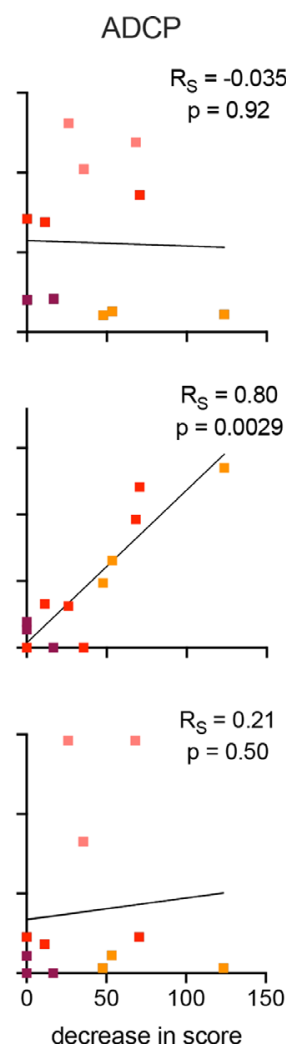

FIGURE 6 | Impact of isotype depletion on antibody functions in nasal wash samples. (A-C) Scatterplots depicting the relationship between the extent of depletion of $\lg A(\mathbf{A}), \lg G(\mathbf{B})$, and $\lg M(\mathbf{C})$ and neutralization (left) and monocyte phagocytosis (right, ADCP) in nasal wash samples. Samples from four different individuals (indicated in color) were processed to deplete each of the three isotypes. Best fit line is illustrated. Spearman correlations $\left(R_{S}\right)$ and two-tailed significance values are indicated in inset.

animal models, have been observed in the serum of convalescent individuals who experienced severe infection $(57,59)$. Infected subjects with mild symptoms may not seroconvert (60-62). While information on systemic immune responses to SARS$\mathrm{CoV}-2$ continues to rapidly accrue, further questions remain about mucosal immune responses to the virus within the respiratory tract - the primary site of SARS-CoV-2 infection and replication (33) and where IgA is the dominant $\mathrm{Ab}$ isotype (63-65).

We sought to characterize the humoral immune response against SARS-CoV-2 with an emphasis on defining distinct features and functions associated with antibodies from the systemic and mucosal compartments. We examined the CoVspecific $\mathrm{Ab}$ response across a panel of SARS-CoV-2 antigens and four other endemic human CoVs. Intriguingly, though an effect of subject age and prior infection history cannot be excluded, Abs that bound to endemic $\mathrm{CoV}$ were elevated among SARS-CoV-2 convalescent donors when compared to naïve controls. While the early appearance of CoV-specific IgG in a subset of patients $(66,67)$ is suggestive of a recall response, data presented here

cannot define whether these Abs are cross-reactive with other endemic $\mathrm{CoV}$, or may represent a more general boosting phenomenon. Consistent with the hypothesis that boosted Abs are cross-reactive, SARS-CoV-2 S-reactive $\mathrm{CD}^{+}{ }^{+} \mathrm{T}$ cells, a prerequisite for class-switched $\mathrm{Ab}$ responses, have been detected in the majority of COVID-19 patients and in 34\% of uninfected individuals, supporting the existence of shared epitopes between $\mathrm{S}$ proteins of endemic $\mathrm{CoV}$ and SARS-CoV-2 (68-70). A similar phenomenon has been observed in immunofluorescence assays $(11,33)$. While many potential explanations exist, the observation that older individuals are most prone to severe COVID-19 illness, combined with the fact that the elderly have a decreased ability to generate de novo Abs (71-73), raises the possibility that pre-existing immunological memory from prior exposure to circulating CoVs (OC43, 229E, HKU1, and NL63) (74) resulting in the induction of poorly neutralizing but cross-reactive Abs may be associated with severe COVID-19 illness (75). To date, the results of other studies investigating this possibility have conflicted, with some concluding that recent endemic $\mathrm{CoV}$ infection could provide some benefit (76) while others suggest the absence of an impact (32). Thus, understanding the influence of pre-existing responses to endemic $\mathrm{CoV}$ remains an outstanding and important are of study.

Both multiplexed $\mathrm{Ab}$ profiling and functional assays showed induction of a generally robust humoral response against SARSCoV-2 in the majority of subjects, but mild cases occasionally lacked serum $(57,61)$ or nasal responses. Indeed, the magnitude of the humoral response in serum appeared to be closely tied to the clinical severity of infection. Closer dissection of the humoral response revealed that it was primarily comprised of IgG1 and IgG3 - subclasses that readily promote effector function via their Fc domains and which were, along with Fc $\gamma$ R-binding SARS$\mathrm{CoV}$-2-specific Abs, associated with diverse effector functions.

These observations suggest that SARS-CoV-2-specific Abs have the potential to contribute to protection against COVID-19 through the involvement of cells of the innate immune system and the complement system, and not solely by neutralization. While much has been made of the potential for Ab responses to promote infection or inflammation via interactions with FcRs or via other mechanisms (77-79), it remains unclear whether the elevated IgG response magnitude is a cause or effect of increased disease severity (80). Limitations to functional characterization reported here include use of surrogate endpoints of anti-viral activities, such as the substitution of FcyR3a activation and complement $\mathrm{C} 3 \mathrm{~b}$ deposition as alternatives to assessing infected cell death or viral lysis, and the use of pseudovirus in neutralization tests and recombinant $S$ proteins in effector function assays. However, assays simplified in these ways have served as correlates of vaccine efficacy in multiple human and animal model studies (81-86) and represent approaches readily available for deployment in the global effort to understand responses to SARS-CoV-2 infection and define protective immunity.

Independent of where antibodies fall on a protectivepathogenic spectrum, the characteristics of the responses 
observed in serum and nasal samples tended to be highly distinct. Not only did the $\mathrm{Ab}$ profiles from individual subjects tend to favor either IgG or IgA, these isotypes showed variable relationships to neutralization activity depending on the site. SARS-CoV-2-specific IgG in serum was associated with neutralization, consistent with prior work demonstrating that neutralizing serum antibodies targeting SARS-CoV-1 and SARSCoV-2 are highly correlated with IgG response magnitude $(57,87)$. In contrast, those subjects who mounted a relatively IgA-biased nasal response exhibited elevated nasal wash neutralization activity, suggesting that the mechanistic contribution of mucosal IgA to neutralization of virus at the portal of entry could be substantial. To this end, while confounded by concomitant effects on unintended isotypes, depletion experiments support the mechanistic relevance of IgG responses to mucosal Ab-mediated phagocytosis, and IgA and IgM to mucosal Ab-mediated neutralization. The observation that those subjects whose nasal specimens had the greatest neutralization potency also tended to report experiencing only mild or moderate symptoms suggests that virus neutralization by mucosal IgA could be relevant to disease outcomes. It is important to note however, that the available cohort was not large enough to adequately power a robust examination of this trend, and further studies will be needed to support this association. Reduced SARS-CoV-2-specific humoral responses among subjects with mild disease also confound the ability to identify potential correlates of reduced severity of disease among these convalescent donors. Several individuals appeared not to "naso" convert, and one mild case failed to seroconvert according to clinical testing. Further, because of the many correlations observed between Ab types and activities in different anatomical sites, additional depletion and other follow up studies will be needed to further define the mechanistic relevance of feature-function correlations and their potential to make causal contributions to modifying disease severity. Though $\operatorname{IgA}$ responses may show poorer durability than $\operatorname{IgG}(88,89)$, taken together with prior studies of other CoV in humans and animals (35-40), these data raise the possibility that levels of SARS-CoV-2-specific mucosal IgA could serve as a useful immune correlate for mitigated disease severity, protection from infection, and reduced likelihood of transmission.

These data have important implications for our understanding of the protection afforded by vaccination or prior infection. When considering vaccine development, an ideal candidate would not only protect the recipient from disease but would also prevent them from serving as an asymptomatic vector, as can be the case in other vaccine-treatable diseases such as polio and pertussis (90-92). Polio is a particularly informative model in this respect as the mucosally-administered and actively replicating form of the vaccine is capable of providing sterilizing immunity - at the expense of a risk of reversion to virulence-while the systemically administered inactivated vaccine fails to induce mucosal immunity and thus serves primarily to protect the recipient from neurological sequelae (58). Our current observation that natural infection elicits alternatively IgG or IgA-biased responses, with IgG associated with serum neutralization potency but severe disease and IgA associated with nasal neutralization activity and mild to moderate disease, suggests that such a dichotomy could exist for COVID-19 as well. While correlates of protection against SARS-CoV-2 in humans have yet to be defined, lessons from related $\mathrm{CoV}$ in animals and humans are consistent with the results of this small natural infection history study; mucosal IgA is likely of substantial importance.

\section{DATA AVAILABILITY STATEMENT}

The original contributions presented in the study are included in the article/Supplementary Material. Further inquiries can be directed to the corresponding authors.

\section{ETHICS STATEMENT}

The studies involving human participants were reviewed and approved by Dartmouth College and Dartmouth-Hitchcock Medical Center Committee for the Protection of Human Subjects. The patients/participants provided their written informed consent to participate in this study.

\section{AUTHOR CONTRIBUTIONS}

Conceptualization: $\mathrm{PW}$ and MA. Investigation: SB, AC, HN, WW-A, and RC. Writing-original draft: SB, AC, HN, JL, MA. Writing-review and editing: all authors. Data analysis and curation: SB, AC, HN, SX, JW, CB, DM, RC. Supervision: PW and MA. Project Administration: JW, WW-A. Funding acquisition: SB, PW, and MA. All authors contributed to the article and approved the submitted version.

\section{FUNDING}

This work was supported by NIH NCI supplement to 2 P30 CA 023108-41, the BioMT Molecular Tools Core supported by NIGMS COBRE award P20-GM113132, Bill and Melinda Gates' Foundation OPP1104756, and by DHMC for providing support for collection of initial cohort samples. SB is supported by NIH NIAID 2T32AI007363.

\section{ACKNOWLEDGMENTS}

VSV-g and SARS-CoV-2 expression plasmids were provided by Dr. Michael Letko (Rocky Mountain Laboratories), CoV S-2P and RBD-Fc expression constructs were provided by Dr. Jason McLellan (UT Austin), and fusion peptide was provided by Dr. Laura Walker and Mrunal Sakharkar (Adimab). The following reagent was produced under HHSN272201400008C and 
obtained through BEI Resources, NIAID, NIH: Spike Glycoprotein Receptor Binding Domain (RBD) from SARSRelated Coronavirus 2, Wuhan-Hu-1 with C-Terminal Histidine Tag, Recombinant from Baculovirus, NR-52307. The authors thank Alejandra Prevost-Reilly, Dr. Anais Ovalle, and Dr. David de Gijsel for support of clinical specimen collection and donor enrollment, Drs. Paul and Cheryl Guyre for critical feedback and editorial assistance, and Dr. Paul Guyre, Jane Collins, and Jonell Hamilton for blood samples and assistance

\section{REFERENCES}

1. ter Meulen J, van den Brink EN, Poon LLM, Marissen WE, Leung CSW, Cox F, et al. Human Monoclonal Antibody Combination against SARS Coronavirus: Synergy and Coverage of Escape Mutants. PLoS Med (2006) 3:e237. doi: 10.1371/journal.pmed.0030237

2. Traggiai E, Becker S, Subbarao K, Kolesnikova L, Uematsu Y, Gismondo MR, et al. An efficient method to make human monoclonal antibodies from memory B cells: potent neutralization of SARS coronavirus. Nat Med (2004) 10:871-5. doi: 10.1038/nm1080

3. Sui J, Li W, Murakami A, Tamin A, Matthews LJ, Wong SK, et al. Potent neutralization of severe acute respiratory syndrome (SARS) coronavirus by a human $\mathrm{mAb}$ to $\mathrm{S} 1$ protein that blocks receptor association. Proc Natl Acad Sci U S A (2004) 101:2536. doi: 10.1073/pnas.0307140101

4. Zhu Z, Chakraborti S, He Y, Roberts A, Sheahan T, Xiao X, et al. Potent crossreactive neutralization of SARS coronavirus isolates by human monoclonal antibodies. Proc Natl Acad Sci (2007) 104:12123. doi: 10.1073/pnas. 0701000104

5. Chan CM, Tse H, Wong SSY, Woo PCY, Lau SKP, Chen L, et al. Examination of seroprevalence of coronavirus HKU1 infection with S protein-based ELISA and neutralization assay against viral spike pseudotyped virus. J Clin Virol (2009) 45:54-60. doi: 10.1016/j.jcv.2009.02.011

6. Wang C, Li W, Drabek D, Okba NMA, van Haperen R, Osterhaus ADME, et al. A human monoclonal antibody blocking SARS-CoV-2 infection. bioRxiv (2020) 2020.03.11.987958. doi: 10.1101/2020.03.11.987958

7. Ye L, Chen X, Li R, Pan Z, Qian C, Yang Y, et al. Human monoclonal antibodies block the binding of SARS-CoV-2 spike protein to angiotensin converting enzyme 2 receptor. medRxiv (2020) 2020.04.06.20055475. doi: 10.1101/2020.04.06.20055475

8. Chen X, Li R, Pan Z, Qian C, Yang Y, You R, et al. Human monoclonal antibodies block the binding of SARS-CoV-2 spike protein to angiotensin converting enzyme 2 receptor. Cell Mol Immunol (2020) 17:647-9. doi: 10.1038/s41423-020-0426-7

9. Wec AZ, Wrapp D, Herbert AS, Maurer DP, Haslwanter D, Sakharkar M, et al. Broad neutralization of SARS-related viruses by human monoclonal antibodies. Science (New York N Y) (2020) 369(6504):731-6. doi: 10.1126/science.abc7424

10. Cao Y, Su B, Guo X, Sun W, Deng Y, Bao L, et al. Potent neutralizing antibodies against SARS-CoV-2 identified by high-throughput single-cell sequencing of convalescent patients' B cells. Cell (2020) 182(1):P73-84.e16. doi: 10.1016/j.cell.2020.05.025

11. Yuan M, Liu H, Wu NC, Lee C-CD, Zhu X, Zhao F, et al. Structural basis of a public antibody response to SARS-CoV-2. BioRxiv Preprint Server Biol (2020) 2020.06.08.141267. doi: 10.1101/2020.06.08.141267

12. Pinto D, Park YJ, Beltramello M, Walls AC, Tortorici MA, Bianchi C, et al. Cross-neutralization of SARS-CoV-2 by a human monoclonal SARS-CoV antibody. Nature (2020) 583:290-5. doi: 10.1038/s41586-020-2349-y

13. Ju B, Zhang Q, Ge J, Wang R, Sun J, Ge X, et al. Human neutralizing antibodies elicited by SARS-CoV-2 infection. Nature (2020) 584:115-9. doi: 10.1038/s41586-020-2380-z

14. Wu Y, Wang F, Shen C, Peng W, Li D, Zhao C, et al. A noncompeting pair of human neutralizing antibodies block COVID-19 virus binding to its receptor ACE2. Science (New York N Y) (2020) 368:1274-8. doi: 10.1126/science.abc2241

15. Shi R, Shan C, Duan X, Chen Z, Liu P, Song J, et al. A human neutralizing antibody targets the receptor binding site of SARS-CoV-2. Nature (2020) 584:120-4. doi: 10.1038/s41586-020-2381-y with neutrophil studies. A prior version of this manuscript has been released as a pre-print at medRxiv (93).

\section{SUPPLEMENTARY MATERIAL}

The Supplementary Material for this article can be found online at: https://www.frontiersin.org/articles/10.3389/fimmu.2020. 618685/full\#supplementary-material

16. Salazar E, Perez KK, Ashraf M, Chen J, Castillo B, Christensen PA, et al. Treatment of Coronavirus Disease 2019 (COVID-19) Patients with Convalescent Plasma. Am J Pathol (2020) 190(8):P1680-90. doi: 10.1016/ j.ajpath.2020.05.014

17. Rogers TF, Zhao F, Huang D, Beutler N, Burns A, He WT, et al. Isolation of potent SARS-CoV-2 neutralizing antibodies and protection from disease in a small animal model. Science (New York N Y) (2020) 369(6506):956-63. doi: $10.1126 /$ science.abc7520

18. Hassan AO, Case JB, Winkler ES, Thackray LB, Kafai NM, Bailey AL, et al. A SARS-CoV-2 Infection Model in Mice Demonstrates Protection by Neutralizing Antibodies. Cell (2020) 182(3):P744-53.E4. doi: 10.1016/j.cell.2020.06.011

19. Imai M, Iwatsuki-Horimoto K, Hatta M, Loeber S, Halfmann PJ, Nakajima N, et al. Syrian hamsters as a small animal model for SARS-CoV-2 infection and countermeasure development. Proc Natl Acad Sci U S A (2020) 117:16587-95. doi: 10.1073/pnas.2009799117

20. Chandrashekar A, Liu J, Martinot AJ, McMahan K, Mercado NB, Peter L, et al. SARS-CoV-2 infection protects against rechallenge in rhesus macaques. Science (New York N Y) (2020) 369(6505):812-7. doi: 10.1126/science.abc4776

21. Yu J, Tostanoski LH, Peter L, Mercado NB, McMahan K, Mahrokhian SH, et al. DNA vaccine protection against SARS-CoV-2 in rhesus macaques. Science (New York N Y) (2020) 369(6505):806-11. doi: 10.1126/ science.abc6284

22. Corbett KS, Flynn B, Foulds KE, Francica S, Boyoglu-Barnum S, Werner AP, et al. Evaluation of the mRNA-1273 Vaccine against SARS-CoV-2 in Nonhuman Primates. N Engl J Med (2020) 383:1544-55. doi: 10.1056/ NEJMoa2024671

23. Mercado NB, Zahn R, Wegmann F, Loos C, Chandrashekar A, Yu J, et al. Single-shot Ad26 vaccine protects against SARS-CoV-2 in rhesus macaques. Nature (2020) 586:583-8. doi: 10.1038/s41586-020-2607-z

24. Tostanoski LH, Wegmann F, Martinot AJ, Loos C, McMahan K, Mercado NB, et al. Ad26 vaccine protects against SARS-CoV-2 severe clinical disease in hamsters. Nat Med (2020) 26:1694-700. doi: 10.1038/s41591-020-1070-6

25. Shen C, Wang Z, Zhao F, Yang Y, Li J, Yuan J, et al. Treatment of 5 Critically Ill Patients With COVID-19 With Convalescent Plasma. JAMA (2020) 323 (16):1582-9. doi: 10.1001/jama.2020.4783

26. Zhang B, Liu S, Tan T, Huang W, Dong Y, Chen L, et al. Treatment With Convalescent Plasma for Critically Ill Patients With SARS-CoV-2 Infection. Chest (2020) 158(1):E9-13. doi: 10.1016/j.chest.2020.03.039

27. Xu TM, Lin B, Chen C, Liu LG, Xue Y. Non-optimal effectiveness of convalescent plasma transfusion and hydroxychloroquine in treating COVID-19: a case report. Virol J (2020) 17:80. doi: 10.1186/s12985-02001354-6

28. Zeng QL, Yu ZJ, Gou JJ, Li GM, Ma SH, Zhang GF, et al. Effect of Convalescent Plasma Therapy on Viral Shedding and Survival in Patients With Coronavirus Disease 2019. J Infect Dis (2020) 222:38-43. doi: 10.1093/ infdis/jiaa228

29. Duan K, Liu B, Li C, Zhang H, Yu T, Qu J, et al. Effectiveness of convalescent plasma therapy in severe COVID-19 patients. Proc Natl Acad Sci U S A (2020) 117:9490-6. doi: 10.1073/pnas.2004168117

30. Chen Y, Zuiani A, Fischinger S, Mullur J, Atyeo C, Travers M, et al. Quick COVID-19 Healers Sustain Anti-SARS-CoV-2 Antibody Production. Cell (2020) 183(6):P1496-507.E16. doi: 10.1016/j.cell.2020.10.051

31. Atyeo C, Fischinger S, Zohar T, Slein MD, Burke J, Loos C, et al. Distinct Early Serological Signatures Track with SARS-CoV-2 Survival. Immunity (2020) 53:524-532 e524. doi: 10.1016/j.immuni.2020.07.020 
32. Loos C, Atyeo C, Fischinger S, Burke J, Slein MD, Streeck H, et al. Evolution of Early SARS-CoV-2 and Cross-Coronavirus Immunity. mSphere (2020) 5. doi: $10.1128 / \mathrm{mSphere} .00622-20$

33. Wölfel R, Corman VM, Guggemos W, Seilmaier M, Zange S, Müller MA, et al. Virological assessment of hospitalized patients with COVID-2019. Nature (2020) 581:465-9. doi: 10.1038/s41586-020-2196-x

34. Krammer F. SARS-CoV-2 vaccines in development. Nature (2020) 586:51627. doi: 10.1038/s41586-020-2798-3

35. Callow KA. Effect of specific humoral immunity and some non-specific factors on resistance of volunteers to respiratory coronavirus infection. J Hyg (Lond) (1985) 95:173-89. doi: 10.1017/s0022172400062410

36. Loa CC, Lin TL, Wu CC, Bryan T, Hooper T, Schrader D. Specific mucosal IgA immunity in turkey poults infected with turkey coronavirus. Vet Immunol Immunopathol (2002) 88:57-64. doi: 10.1016/s0165-2427(02)00135-6

37. Pearson M, LaVoy A, Evans S, Vilander A, Webb C, Graham B, et al. Mucosal Immune Response to Feline Enteric Coronavirus Infection. Viruses (2019) 11 (10):906. doi: 10.3390/v11100906

38. Saif LJ. Development of nasal, fecal and serum isotype-specific antibodies in calves challenged with bovine coronavirus or rotavirus. Vet Immunol Immunopathol (1987) 17:425-39. doi: 10.1016/0165-2427(87)90159-0

39. Du L, Zhao G, Lin Y, Sui H, Chan C, Ma S, et al. Intranasal vaccination of recombinant adeno-associated virus encoding receptor-binding domain of severe acute respiratory syndrome coronavirus (SARS-CoV) spike protein induces strong mucosal immune responses and provides long-term protection against SARS-CoV infection. J Immunol (2008) 180:948-56. doi: 10.4049/ jimmunol.180.2.948

40. See RH, Zakhartchouk AN, Petric M, Lawrence DJ, Mok CP, Hogan RJ, et al. Comparative evaluation of two severe acute respiratory syndrome (SARS) vaccine candidates in mice challenged with SARS coronavirus. J Gen Virol (2006) 87:641-50. doi: 10.1099/vir.0.81579-0

41. Moreno-Fierros L, Garcia-Silva I, Rosales-Mendoza S. Development of SARSCoV-2 vaccines: should we focus on mucosal immunity? Expert Opin Biol Ther (2020) 20(8):831-36. doi: 10.1080/14712598.2020.1767062

42. Boesch AW, Brown EP, Cheng HD, Ofori MO, Normandin E, Nigrovic PA, et al. Highly parallel characterization of IgG Fc binding interactions. MAbs (2014) 6:915-27. doi: $10.4161 /$ mabs.28808

43. Brown EP, Licht AF, Dugast AS, Choi I, Bailey-Kellogg C, Alter G, et al. Highthroughput, multiplexed IgG subclassing of antigen-specific antibodies from clinical samples. J Immunol Methods (2012) 386:117-23. doi: 10.1016/ j.jim.2012.09.007

44. Brown EP, Dowell KG, Boesch AW, Normandin E, Mahan AE, Chu T, et al. Multiplexed Fc array for evaluation of antigen-specific antibody effector profiles. J Immunol Methods (2017) 443:33-44. doi: 10.1016/j.jim.2017.01.010

45. Brown EP, Weiner JA, Lin S, Natarajan H, Normandin E, Barouch DH, et al. Optimization and qualification of an Fc Array assay for assessments of antibodies against HIV-1/SIV. J Immunol Methods (2018) 455:24-33. doi: $10.1016 /$ j.jim.2018.01.013

46. Letko M, Marzi A, Munster V. Functional assessment of cell entry and receptor usage for SARS-CoV-2 and other lineage B betacoronaviruses. Nat Microbiol (2020) 5:562-9. doi: 10.1038/s41564-020-0688-y

47. Ackerman ME, Moldt B, Wyatt RT, Dugast AS, McAndrew E, Tsoukas S, et al. A robust, high-throughput assay to determine the phagocytic activity of clinical antibody samples. J Immunol Methods (2011) 366:8-19. doi: 10.1016/j.jim.2010.12.016

48. McAndrew EG, Dugast AS, Licht AF, Eusebio JR, Alter G, Ackerman ME. Determining the phagocytic activity of clinical antibody samples. J Vis Exp JoVE (2011) e3588. doi: 10.3791/3588

49. Karsten CB, Mehta N, Shin SA, Diefenbach TJ, Slein MD, Karpinski W, et al. A versatile high-throughput assay to characterize antibody-mediated neutrophil phagocytosis. J Immunol Methods (2019) 471:46-56. doi: $10.1016 /$ j.jim.2019.05.006

50. Fischinger S, Fallon JK, Michell AR, Broge T, Suscovich TJ, Streeck H, et al. A high-throughput, bead-based, antigen-specific assay to assess the ability of antibodies to induce complement activation. J Immunol Methods (2019) 473:112630. doi: 10.1016/j.jim.2019.07.002

51. RC Team. R: A Language and Environment for Statistical Computing. In: RFfS Computing, editor. Vienna, Austria (2017).

52. Kolde R. pheatmap: Pretty Heatmaps (2019).
53. Wei T, Simko V. R package "corrplot": Visualization of a Correlation Matrix. (2017).

54. Wickham H. ggplot2: Elegant Graphics for Data Analysis. New York: SpringerVerlag (2009).

55. Pittala S, Morrison KS, Ackerman ME. Systems serology for decoding infection and vaccine-induced antibody responses to HIV-1. Curr Opin HIV AIDS (2019) 14:253-64. doi: 10.1097/COH.0000000000000558

56. Barouch DH, Alter G, Broge T, Linde C, Ackerman ME, Brown EP, et al. Protective efficacy of adenovirus/protein vaccines against SIV challenges in rhesus monkeys. Science (New York N Y) (2015) 349:320-4. doi: 10.1126/science.aab3886

57. Klein S, Pekosz A, Park HS, Ursin R, Shapiro J, Benner S, et al. Sex, age, and hospitalization drive antibody responses in a COVID-19 convalescent plasma donor population. medRxiv (2020). doi: 10.1101/2020.06.26.20139063

58. Wright PF, Connor RI, Wieland-Alter WF, Hoen AG, Boesch AW, Ackerman ME, et al. Vaccine-induced mucosal immunity to poliovirus: analysis of cohorts from an open-label, randomised controlled trial in Latin American infants. Lancet Infect Dis (2016) 16:1377-84. doi: 10.1016/S1473-3099(16)30169-4

59. Long QX, Tang XJ, Shi QL, Li Q, Deng HJ, Yuan J, et al. Clinical and immunological assessment of asymptomatic SARS-CoV-2 infections. Nat Med (2020) 26:1200-4. doi: 10.1038/s41591-020-0965-6

60. Gallais F, Velay A, Wendling M-J, Nazon C, Partisani M, Sibilia J, et al. Intrafamilial Exposure to SARS-CoV-2 Induces Cellular Immune Response without Seroconversion. medRxiv. doi: 10.1101/2020.06.21.20132449

61. Sekine T, Perez-Potti A, Rivera-Ballesteros O, Strålin K, Gorin J-B, Olsson A, et al. Robust $\mathrm{T}$ cell immunity in convalescent individuals with asymptomatic or mild COVID-19. bioRxiv (2020) 2020.06.29.174888. doi: 10.1101/ 2020.06.29.174888

62. Le Bert N, Tan AT, Kunasegaran K, Tham CYL, Hafezi M, Chia A, et al. SARSCoV-2-specific T cell immunity in cases of COVID-19 and SARS, and uninfected controls. Nature (2020) 584:457-62. doi: 10.1038/s41586-020-2550-z

63. Chodirker WB, Tomasi TB Jr. Gamma-Globulins: Quantitative Relationships in Human Serum and Nonvascular Fluids. Science (New York N Y) (1963) 142:1080-1. doi: 10.1126/science.142.3595.1080

64. Tomasi TB Jr, Tan EM, Solomon A, Prendergast RA. Characteristics of an Immune System Common to Certain External Secretions. J Exp Med (1965) 121:101-24. doi: 10.1084/jem.121.1.101

65. Conley ME, Delacroix DL. Intravascular and mucosal immunoglobulin A: two separate but related systems of immune defense? Ann Intern Med (1987) 106:892-9. doi: 10.7326/0003-4819-106-6-892

66. Long Q-X, Deng H-j, Chen J, Hu J, Liu B-z, Liao P, et al. Antibody responses to SARS-CoV-2 in COVID-19 patients: the perspective application of serological tests in clinical practice. medRxiv (2020) 2020.03.18.20038018. doi: $10.1101 / 2020.03 .18 .20038018$

67. Zhao J, Yuan Q, Wang H, Liu W, Liao X, Su Y, et al. Antibody responses to SARS-CoV-2 in patients of novel coronavirus disease 2019. Clin Infect Dis (2020) 71(16):2027-34. doi: 10.1093/cid/ciaa344

68. Braun J, Loyal L, Frentsch M, Wendisch D, Georg P, Kurth F, et al. Presence of SARS-CoV-2 reactive $\mathrm{T}$ cells in COVID-19 patients and healthy donors. medRxiv (2020) 2020.04.17.20061440. doi: 10.1101/2020.04.17.20061440

69. Grifoni A, Sidney J, Zhang Y, Scheuermann RH, Peters B, Sette A. A Sequence Homology and Bioinformatic Approach Can Predict Candidate Targets for Immune Responses to SARS-CoV-2. Cell Host Microbe (2020) 27:67180.e672. doi: $10.1016 /$ j.chom.2020.03.002

70. Grifoni A, Weiskopf D, Ramirez SI, Mateus J, Dan JM, Moderbacher CR, et al. Targets of T Cell Responses to SARS-CoV-2 Coronavirus in Humans with COVID-19 Disease and Unexposed Individuals. Cell (2020) 181:1489501.e1415. doi: 10.1016/j.cell.2020.05.015

71. de Bourcy CF, Angel CJ, Vollmers C, Dekker CL, Davis MM, Quake SR. Phylogenetic analysis of the human antibody repertoire reveals quantitative signatures of immune senescence and aging. Proc Natl Acad Sci U S A (2017) 114:1105-10. doi: 10.1073/pnas.1617959114

72. Gibson KL, Wu YC, Barnett Y, Duggan O, Vaughan R, Kondeatis E, et al. Bcell diversity decreases in old age and is correlated with poor health status. Aging Cell (2009) 8:18-25. doi: 10.1111/j.1474-9726.2008.00443.x

73. Henry C, Zheng NY, Huang M, Cabanov A, Rojas KT, Kaur K, et al. Influenza Virus Vaccination Elicits Poorly Adapted B Cell Responses in Elderly Individuals. Cell Host Microbe (2019) 25:357-66.e356. doi: 10.1016/ j.chom.2019.01.002 
74. Ng K, Faulkner N, Cornish G, Rosa A, Earl C, Wrobel A, et al. Pre-existing and de novo humoral immunity to SARS-CoV-2 in humans. bioRxiv (2020) 2020.05.14.095414. doi: 10.1101/2020.05.14.095414

75. Tetro JA. Is COVID-19 receiving ADE from other coronaviruses? Microbes Infect (2020) 22:72-3. doi: 10.1016/j.micinf.2020.02.006

76. Sagar M, Reifler K, Rossi M, Miller NS, Sinha P, White L, et al. Recent endemic coronavirus infection is associated with less severe COVID-19. J Clin Invest (2020). doi: 10.1172/JCI143380

77. Wang Q, Zhang L, Kuwahara K, Li L, Liu Z, Li T, et al. Immunodominant SARS Coronavirus Epitopes in Humans Elicited both Enhancing and Neutralizing Effects on Infection in Non-human Primates. ACS Infect Dis (2016) 2:361-76. doi: 10.1021/acsinfecdis.6b00006

78. Arvin AM, Fink K, Schmid MA, Cathcart A, Spreafico R, Havenar-Daughton $\mathrm{C}$, et al. A perspective on potential antibody-dependent enhancement of SARS-CoV-2. Nature (2020) 584:353-63. doi: 10.1038/s41586-020-2538-8

79. Eroshenko N, Gill T, Keaveney MK, Church GM, Trevejo JM, Rajaniemi H. Implications of antibody-dependent enhancement of infection for SARSCoV-2 countermeasures. Nat Biotechnol (2020) 38:789-91. doi: 10.1038/ s41587-020-0577-1

80. Huang AT, Garcia-Carreras B, Hitchings MDT, Yang B, Katzelnick LC, Rattigan $\mathrm{SM}$, et al. A systematic review of antibody mediated immunity to coronaviruses: antibody kinetics, correlates of protection, and association of antibody responses with severity of disease. medRxiv (2020). doi: 10.1101/2020.04.14.20065771

81. Ackerman ME, Das J, Pittala S, Broge T, Linde C, Suscovich TJ, et al. Route of immunization defines multiple mechanisms of vaccine-mediated protection against SIV. Nat Med (2018) 24:1590-8. doi: 10.1038/s41591-018-0161-0

82. Felber BK, Lu Z, Hu X, Valentin A, Rosati M, Remmel CAL, et al. Coimmunization of DNA and Protein in the Same Anatomical Sites Induces Superior Protective Immune Responses against SHIV Challenge. Cell Rep (2020) 31:107624. doi: 10.1016/j.celrep.2020.107624

83. Miller-Novak LK, Das J, Musich TA, Demberg T, Weiner JA, Venzon DJ, et al. Analysis of Complement-Mediated Lysis of Simian Immunodeficiency Virus (SIV) and SIV-Infected Cells Reveals Sex Differences in Vaccine-Induced Immune Responses in Rhesus Macaques. J Virol (2018) 92. doi: 10.1128/JVI.00721-18

84. Om K, Paquin-Proulx D, Montero M, Peachman K, Shen X, Wieczorek L, et al. Adjuvanted HIV-1 vaccine promotes antibody-dependent phagocytic responses and protects against heterologous SHIV challenge. PLoS Pathog (2020) 16:e1008764. doi: 10.1371/journal.ppat.1008764

85. Suscovich TJ, Fallon JK, Das J, Demas AR, Crain J, Linde CH, et al. Mapping functional humoral correlates of protection against malaria challenge following RTS,S/AS01 vaccination. Sci Transl Med (2020) 12(553):eabb4757. doi: 10.1126/scitranslmed.abb4757

86. Neidich SD, Fong Y, Li SS, Geraghty DE, Williamson BD, Young WC, et al. Antibody Fc effector functions and IgG3 associate with decreased HIV-1 risk. J Clin Invest (2019) 129:4838-49. doi: 10.1172/JCI126391

87. Cao WC, Liu W, Zhang PH, Zhang F, Richardus JH. Disappearance of antibodies to SARS-associated coronavirus after recovery. N Engl J Med (2007) 357:1162-3. doi: 10.1056/NEJMc070348

88. Isho B, Abe KT, Zuo M, Jamal AJ, Rathod B, Wang JH, et al. Persistence of serum and saliva antibody responses to SARS-CoV-2 spike antigens in COVID-19 patients. Sci Immunol (2020) 5(52):eabe5511. doi: 10.1126/ sciimmunol.abe5511

89. Iyer AS, Jones FK, Nodoushani A, Kelly M, Becker M, Slater D, et al. Persistence and decay of human antibody responses to the receptor binding domain of SARS-CoV-2 spike protein in COVID-19 patients. Sci Immunol (2020) 5(52):eabe0367. doi: 10.1126/sciimmunol.abe0367

90. Holmgren J, Czerkinsky C. Mucosal immunity and vaccines. Nat Med (2005) 11:S45-53. doi: $10.1038 / \mathrm{nm} 1213$

91. Warfel JM, Zimmerman LII, Merkel TJ. Acellular pertussis vaccines protect against disease but fail to prevent infection and transmission in a nonhuman primate model. Proc Natl Acad Sci U S A (2014) 111:787-92. doi: 10.1073/ pnas. 1314688110

92. Althouse BM, Scarpino SV. Asymptomatic transmission and the resurgence of Bordetella pertussis. BMC Med (2015) 13:146. doi: 10.1186/s12916-015-0382-8

93. Butler SE, Crowley AR, Natarajan H, Xu S, Weiner JA, Lee J, et al. Features and Functions of Systemic and Mucosal Humoral Immunity Among SARSCoV-2 Convalescent Individuals. medRxiv (2020). doi: 10.1101/ 2020.08.05.20168971

Conflict of Interest: The authors declare that the research was conducted in the absence of any commercial or financial relationships that could be construed as a potential conflict of interest.

Copyright (C) 2021 Butler, Crowley, Natarajan, Xu, Weiner, Bobak, Mattox, Lee, Wieland-Alter, Connor, Wright and Ackerman. This is an open-access article distributed under the terms of the Creative Commons Attribution License (CC BY). The use, distribution or reproduction in other forums is permitted, provided the original author(s) and the copyright owner(s) are credited and that the original publication in this journal is cited, in accordance with accepted academic practice. No use, distribution or reproduction is permitted which does not comply with these terms. 